\title{
Data driven analysis of low frequency spatio- temporal dynamics in resting state MRI (rsMRI) data
}

\author{
Martha Willis ${ }^{*}$, Lukas Hoffman², Alessio Medda', Shella Keilholz ${ }^{2}$ \\ From Twenty First Annual Computational Neuroscience Meeting: CNS*2012 \\ Decatur, GA, USA. 21-26 July 2012
}

Resting state MRI (rsMRI), based on fluctuations in blood oxygenation level dependent (BOLD) signals, serves as a powerful tool to map networks of "functional connectivity" in the brain even in the absence of task activation or stimulation. The most popular analysis techniques for resting state networks involve region of interest (ROI) correlations or Independent Component Analysis (ICA) approaches where the networks are assumed to be undirected and static over the course of the several minute long scan. Recent studies by Majeed
[4] and Chang [5], show that patterns of connectivity exhibit time-varying properties that change significantly over the course of a single scan. Interactions between different areas of the brain exhibit dynamic properties on the order of tens of seconds [4]. This time scale closely corresponds to the temporal scale observed in cognitive processes suggesting that the dynamics of this "background activity" may influence behavior and/or perception. Characterizing and understanding these dynamics presents unique challenges in terms of signal analysis.

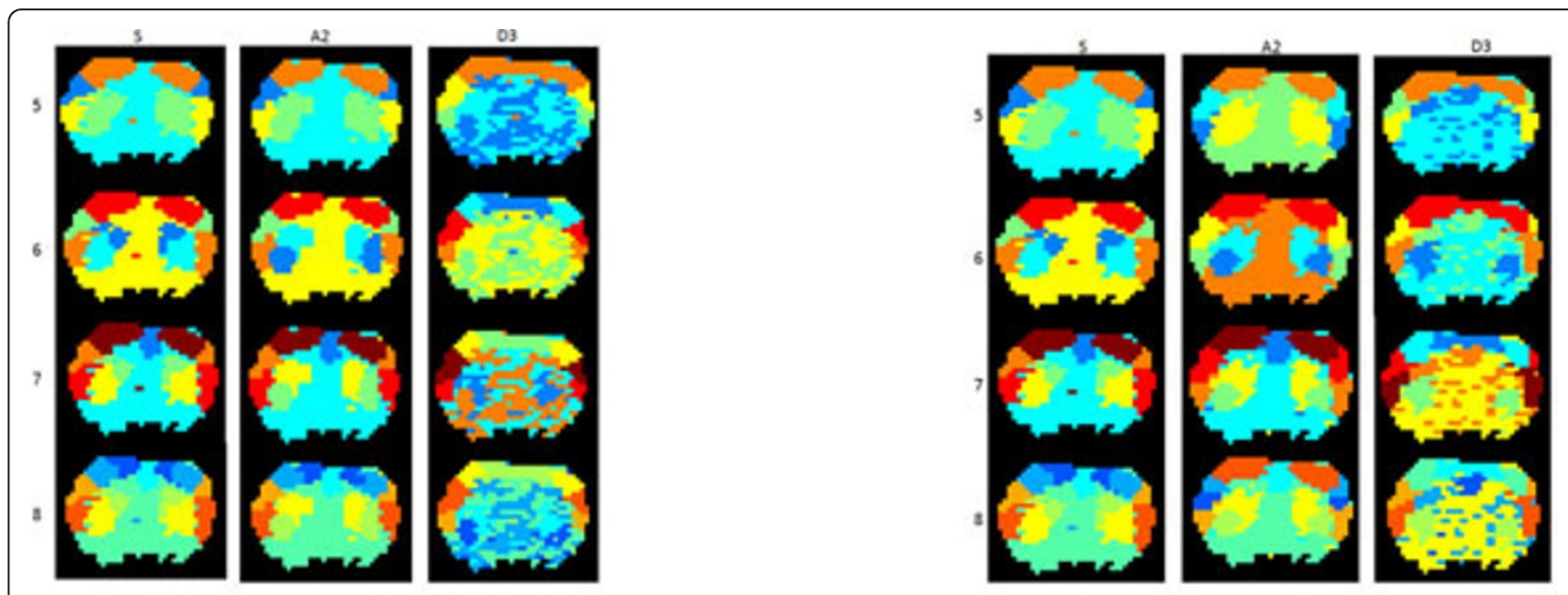

Figure 1 Sample clusters in rat brains. Clusters include original signal (S), A2, and D3 coeffiecients and 5,6,7, and 8 clusters using using two different wavelets. A) Daubechies 12 Wavelet. B) Symlet 8 Wavelet

* Correspondence: martha.willis@gtri.gatech.edu

'Georgia Tech Research Institute, Atlanta, GA, 30306, USA

Full list of author information is available at the end of the article

(c) 2012 Willis et al; licensee BioMed Central Ltd. This is an Open Access article distributed under the terms of the Creative Commons Attribution License (http://creativecommons.org/licenses/by/2.0), which permits unrestricted use, distribution, and reproduction in any medium, provided the original work is properly cited. 
We are currently optimizing a completely data driven analysis technique based on wavelet features of BOLD time series data.

Wavelets have been used extensively in the analysis of neurological BOLD signals, most commonly, however in task-induced studies with few examples in rsMRI studies. Here we utilize wavelet features of voxel time series, which are clustered using an agglomerative clustering method. The DWT, an algorithm based on subband coding provides a fast computation of the wavelet transform, as in the multiresolution analysis (MRA) algorithm defined by Mallat [6]. A variety of wavelets were compared, and initial results using Daubechies and Symlet wavelets were used to cluster and compare varying numbers of clusters and choice of either approximation (A2) or detail (D3) levels. Figure 1 shows a series of preliminary data for comparison. The successful detection of clusters that match well with classical anatomical boundaries in sensorimotor cortex indicates that wavelet-based segmentation is a promising first step toward data-driven analysis of network dynamics.

\section{Author details}

${ }^{1}$ Georgia Tech Research Institute, Atlanta, GA, 30306, USA. ²Emory University and Georgia Institute of Technology, Atlanta, GA 30306, USA.

Published: 16 July 2012

\section{References}

1. Biswal B, Yetkin FZ, Haughton VM, Hyde JS: Functional conectivity in the motor cortex of resting human using echo planar MRI. Magn Reson Med 1995, 34:537-541.

2. Fox MD, Snyder AZ, Vincent $J$, Corbetta M, Van Essen DC, Raichle ME: The human brain is intrinsically organized into dynamic, anticorrelated functional networks. Proc Natl Acad Sci USA 2005, 102(27):9673-9678.

3. Greicius M: Resting-state functional connectivity in neuropsychiatric disorders. Curr Opin Neuro 2008, 21(4):424-30.

4. Majeed W, Magnuson M, Hasenkamp W, Schwarb H, Schumacher EH, Barsalou L, Keilholz SD: Spatiotemporal dynamics of low frequency BOLD fluctuations in rats and humans. Neuroimage 2011, 54:1140-1150.

5. Chang C, Glover GH: Time-frequency dynamics of resting-state brain connectivity measured with fMRI. Neuroimage 2010, 50(1):81-98.

6. Mallat SG: A theory for multiresolution signal decomposition: the wavelet representation. IEEE Trans Patt Anal Mach Intell 1989, 11:674-693.

doi:10.1186/1471-2202-13-S1-P108

Cite this article as: Willis et al:: Data driven analysis of low frequency spatio-temporal dynamics in resting state MRI (rsMRI) data. BMC Neuroscience 2012 13(Suppl 1):P108.

\section{Submit your next manuscript to BioMed Central and take full advantage of:}

- Convenient online submission

- Thorough peer review

- No space constraints or color figure charges

- Immediate publication on acceptance

- Inclusion in PubMed, CAS, Scopus and Google Scholar

- Research which is freely available for redistribution

Submit your manuscript at www.biomedcentral.com/submit
C Biomed Central 